\title{
Correction to: On the feasibility of automated prediction of bug and non-bug issues
}

\section{Steffen Herbold ${ }^{1} \cdot$ Alexander Trautsch $^{2}$ - Fabian Trautsch ${ }^{2}$}

Published online: 17 October 2020

(C) The Author(s) 2020

\section{Correction to: Empirical Software Engineering https://doi.org/10.1007/s10664-020-09885-w}

The original version of this article unfortunately contained mistakes. Figures 8, 9 and 10 were incorrectly captured. Somehow, the plots in Figure 8 were replaced with those from Figure 9 and the original Figure 8 was lost. The correct versions are as follows.

The online version of the original article can be found at https://doi.org/10.1007/s10664-020-09885-w

\section{Steffen Herbold}

steffen.herbold@kit.edu

Alexander Trautsch

alexander.trautsch@cs.uni-goettingen.de

Fabian Trautsch

fabian.trautsch@cs.uni-goettingen.de

1 Institute AIFB, Karlsruhe Institute of Technology (KIT), Karlsruhe, Germany

2 Institute of Computer Science, University of Goettingen, Gottingen, Germany 


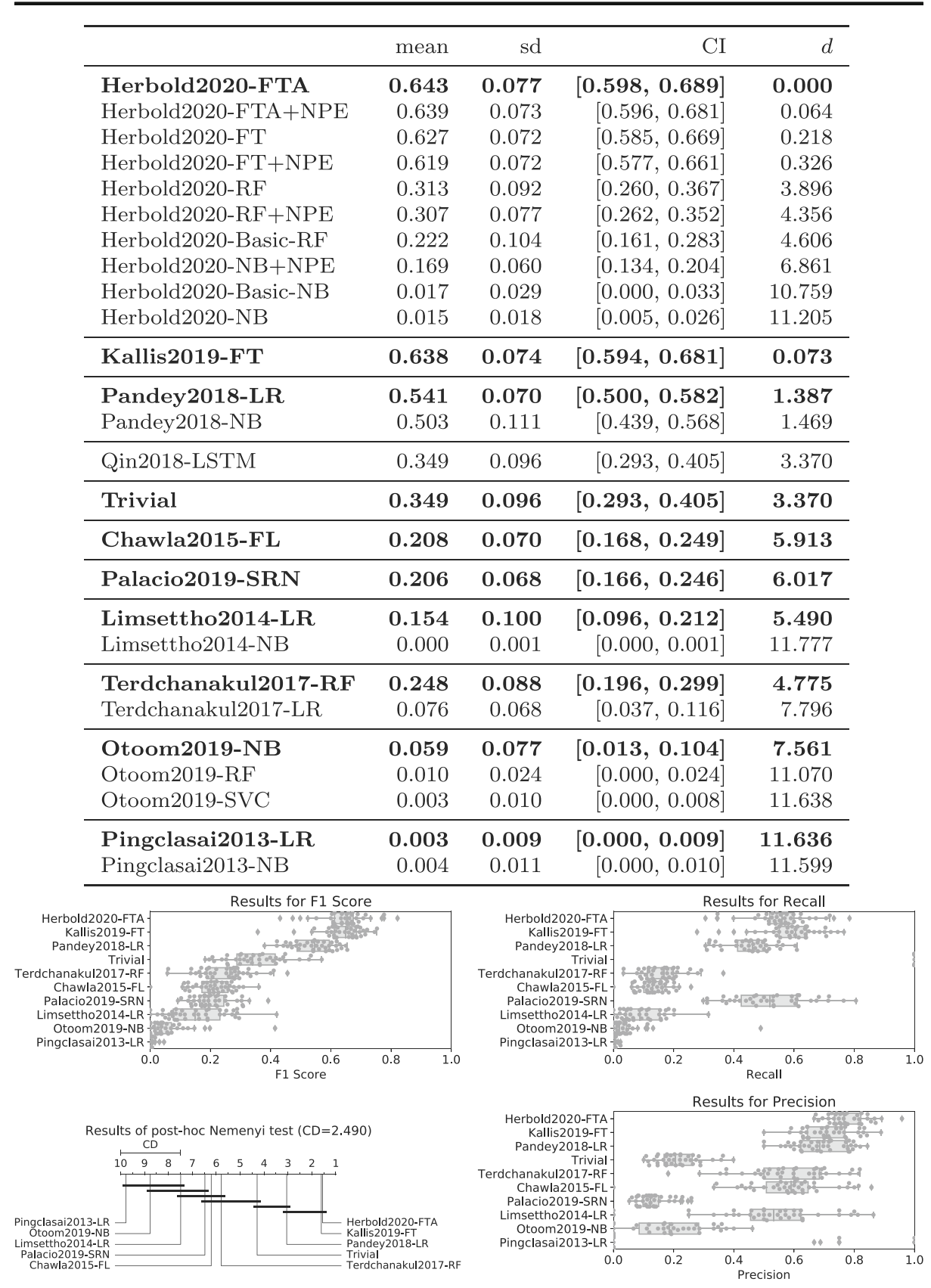

Fig. 8 Results of leave-one-project-out cross validation with the $\mathrm{CV}_{A L L}$ data. The bold-faced approaches where the best for a publication and are used in the statistical analysis 


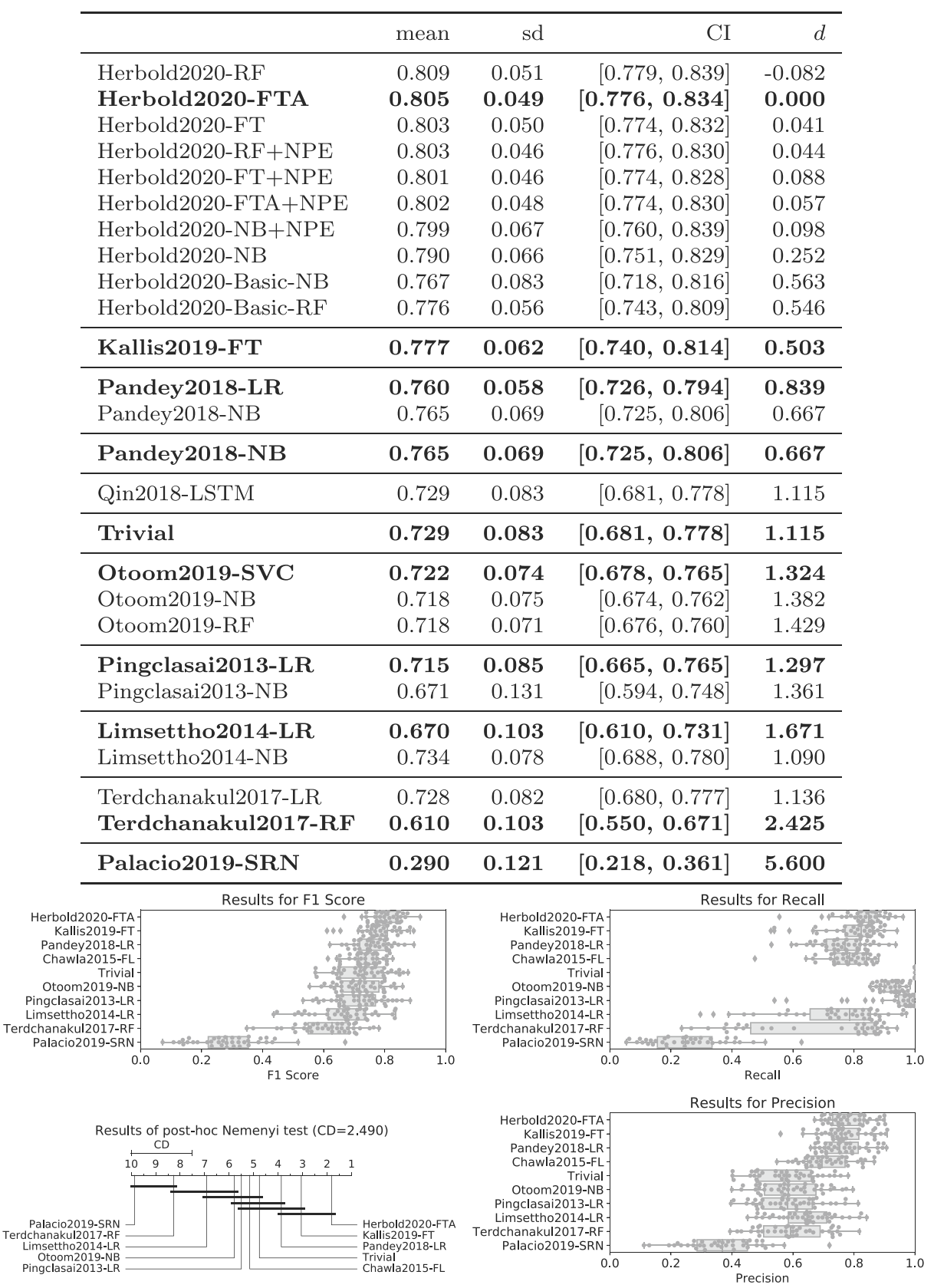

Fig. 9 Results of leave-one-project-out cross validation with the $\mathrm{CV}_{B U G}$ data. The bold-faced approaches where the best for a publication and are used in the statistical analysis 

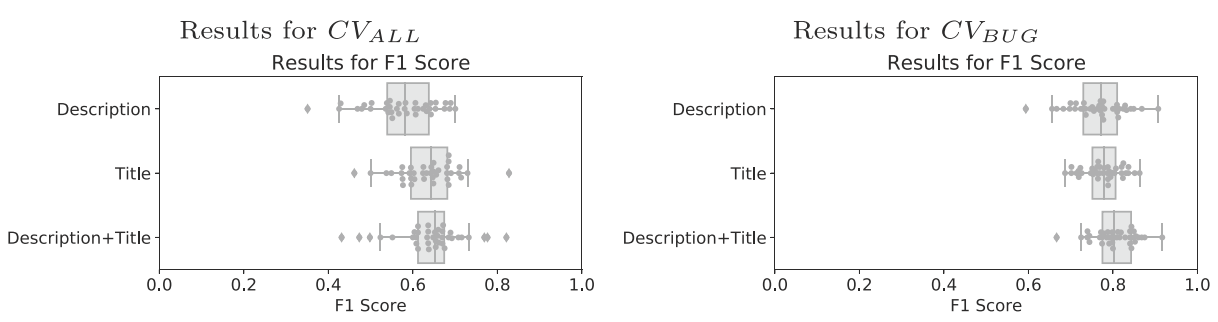

Fig. 10 Results for the different classifiers for tittle and description in comparison to their combination to gain insights into the Herbold2020-FTA model

The original article has been corrected.

Open Access This article is licensed under a Creative Commons Attribution 4.0 International License, which permits use, sharing, adaptation, distribution and reproduction in any medium or format, as long as you give appropriate credit to the original author(s) and the source, provide a link to the Creative Commons licence, and indicate if changes were made. The images or other third party material in this article are included in the article's Creative Commons licence, unless indicated otherwise in a credit line to the material. If material is not included in the article's Creative Commons licence and your intended use is not permitted by statutory regulation or exceeds the permitted use, you will need to obtain permission directly from the copyright holder. To view a copy of this licence, visit http://creativecommons.org/licenses/by/4.0/.

Publisher's note Springer Nature remains neutral with regard to jurisdictional claims in published maps and institutional affiliations. 